\title{
ВОССТАНОВЛЕНИЕ
} ДИПЛОМАТИЧЕСКИХ ОТНОШЕНИЙ С ИСПАНИЕЙ И ЗАКЛЮЧЕНИЕ ПЕРВОГО ДОГОВОРА

\author{
О РАЗОРУЖЕНИИ С США \\ В ВОСПОМИНАНИЯХ \\ Ю.В. ДУБИНИНА
}

Н.Е. Аникеева, Ю.В. Дубинин

Московский государственный институт международных отношений (университет) МИД России. Россия, 119454, Москва, пр. Вернадского, 76.

«Вестник МГИМО-Университета» публикует беседу с выпускником МГИМо, чрезвычайным и Полномочным Послом, профессором кафедры дипломатии МГИМО(У) МИД РФ, заслуженным работником дипломатической службы РФ, членом Совета по внешней и оборонной политике, виче-президентом Академии проблем безопасности, обороны и правопорядка, почетным президентом Ассоциации друзей Франции, первым вице-президентом Академии духовного единства народов мира, членом Союза писателей России, членом Совета по международным делам Ю.В. Дубининым , в которой он поделился своими воспоминаниями о периоде пребывания на посту Посла СССР в Испании и в США. Беседу с Юрием Владимировичем (Ю.Д.) провела и записала д.и.н., профессор кафедры ИПСЕА МГИМО(У) МИД России Н.Е. Аникеева (Н.А.). 
$\mathrm{B}$ олею судьбы на долю Ю.В. Дубинина выпало осуществление целого ряда крупных дипломатических миссий, которые могут на первый взгляд показаться трудно совместимыми друг с другом. В самом деле: Франция и Испания, $\mathrm{OOH} \mathrm{и} \mathrm{США,} \mathrm{наконец} \mathrm{Украина.} \mathrm{В} \mathrm{разное} \mathrm{время}$ он занимал важные государственные посты: Чрезвычайный и Полномочный Посол СССР в Королевстве Испания (1978-1986 гг.), Постоянный представитель СССР при ООН, Чрезвычайный и Полномочный Посол СССР в США (1986-1990 гг.), Чрезвычайный и Полномочный Посол СССР во Французской Республике (19901991 гг.), Чрезвычайный и Полномочный Посол России в Украине в ранге заместителя министра иностранных дел РФ (1996-1999 гг.). С 1991 по 1994 г. - посол по особым поручениям МИД России; в 1994-1996 гг. занимал пост заместителя министра иностранных дел РФ.

Н.А. Уважаемый Юрий Владимирович, руководством МИД СССР Вам было поручено в 1977 г. проведение переговоров о восстановлении дипломатических отношений с Испанией. В 1978 г. Вы были назначены Послом СССР в Мадриде и оставались на этом посту до 1986 г. В то время в Испании уже существовала сложная проблема - баскский терроризм. В своих мемуарах Вы отмечаете, что франкистская пропаганда сумела укоренить в общественном мнении Испании миф о том, что за спиной баскских террористов стоит Советский Союз и его спецслужбы. Не могли бы Вы подробнее рассказать об этой проблеме?

Ю.Д. В 1975 г. не стало Ф. Франко, но террористическая деятельность баскских сепаратистов продолжалась, а с нею жил и враждебный нашей стране миф, раздуваемый реакционными силами. Укоренился он и в официальных кабинетах страны. И в первой же беседе со мной министр иностранных дел Испании М. Ореха, любезно отметив, что вся страна открыта для поездок советского посла, счел необходимым оговориться: «Кроме Страны Басков. Там неспокойно...» А председатель испанского правительства А. Суарес во время нашей первой встречи гипертрофированно выделил тему причастности Советского Союза к террористической деятельности в Испании.

- Посмотрите туда, посол, - заявил он и показал на стоявший в стороне от диванчика, на котором шла беседа, большой письменный стол. Стол был завален бумагами. - Туда, - сказал А. Суарес, - каждый день ложатся многочисленные донесения не только из Испании, но и из-за границы с утверждениями, что за баскскими террористами стоит Москва.

Это был резкий натиск. Я со всей категоричностью заявил, что правды в этих донесениях нет и быть не может.

- Вы можете все эти донесения выбросить в корзину, - сказал я.

А. Суарес отнесся к этим словам с недоверием. Не вступая в спор, он, сдвинув брови, произнес твердым голосом:
- Я внимательно отношусь к вашим словам, посол, но, говоря все это, вы берете на себя большую ответственность!

Ответственность действительно была велика. Мы давали активный отпор клевете в средствах массовой информации Испании, обращались публично к стране со словами: «Испанцы, не верьте!!!»

С разоблачением лжи выступил в Москве и А.А. Громыко. Эффекта это не давало. Тем временем терроризм в Испании разрастался, превращался в кровоточащую рану. Он тяжелым грузом висел на наших отношениях с этой страной. С приходом к власти социалистов испанская реакция даже усилила эксплуатацию темы нашей причастности к этому злу, превратив ее в заслон против улучшения советско-испанских отношений. Чтобы положить этому конец, требовалось предпринять что-то смелое, неординарное. Тогда я принимаю решение совершить поездку в Страну Басков.

Министр внутренних дел Испании Баррионуэво, мой хороший знакомый, не только поддерживал меня, но и обещал усиленную охрану: помимо обычного сопровождения посла в поездках по стране представителями испанской службы безопасности в штатском, на этот раз за мною следовало отделение военной жандармерии на двух джипах. В середине января 1983 г. я с супругой вышел из самолета в Бильбао. Это было первое в истории посещение послом нашей страны Басконии.

В один из четырех дней пребывания здесь я был принят председателем правительства Страны Басков К. Гарайкоэчеа. После того как я вышел из этой его резиденции, я оказался перед плотной стеной журналистов. Выставляя вперед, словно автоматы, свои магнитофоны, фотоаппараты и телекамеры, они, сжимая ряды, берут посла в плотный круг. Обстрел вопросами? Конечно, прежде всего мне задали вопрос на тему «Советский Союз и баскские террористы».

Я решительно опроверг всякую нашу связь с терроризмом, твердо заявив, что наша страна тут не при чем. Вполне понятны вся значимость, весь реальный вес этих моих слов: ведь они прозвучали для всей Испании прямо из Страны Басков, из ее сердца, с порога Лендакари - резиденции премьер - министра этой провинции. Этого не замолчишь, не утаишь.

Вэтот же день средства массовой информации сообщают, что в Стране Басков террористы совершили очередную акцию - похитили мальчика. По обычным стандартам это был вполне подходящий случай, чтобы обрушить очередную порцию выпадов против Советского Союза. Однако на этот раз все происходило иначе. Испанское телевидение вслед за сообщением об исчезновении ребенка дает мой портрет и цитирует мои высказывания из Басконии. Оттуда их действительно услышали.

Не успел я вернуться в Мадрид, как на стол посыпались вырезки из газет всей страны с броскими заголовками: "Советский посол заявляет: связь Со- 
ветского Союза с ЭТА - ложь" (газета из Бильбао), "Посол СССР отвергает причастность своей страны к ЭТА" (газета из Наварры), "Советский посол отрицает взаимодействие КГБ с ЭТА" (газета из Валенсии), "Утверждения об отношениях между КГБ и ЭТА фальшивы. Их следует игнорировать" (газета "Эль Паис" из Мадрида). Гора вырезок из газет быстро растет. Все они были однозначно позитивные - мои высказывания цитировались точно, без искажений. Впервые никто не вступал в спор.

Одна правая газета "Йа" запоздала со своей реакцией на несколько дней. Но потом вместо информационного сообщения о сделанных мною заявлениях газета публикует статью своего ведущего обозревателя академика Рикардо де ля Сиерва, одного из виднейших приверженцев Франко. В этой статье, которую он назвал "Сюрприз со стороны посла", академик взрывается негодованием: как "осмелился посол отрицать связь ЭТА с КГБ?" И где? Находясь в Стране Басков! Но негодование его бессильным. Ему нечего было противопоставить моим словам!

Так из Страны Басков, с порога резиденции главы баскского правительства нам удалось радикально изменить отношение испанского общественного мнения к этой проблеме.

H.A. Четыре года, которые Вы провели в Вашингтоне в качестве Посла СССР (1986-1990 гг.), стали продуктивным периодом качественного улучшения отношений с Америкой и прекращения холодной войны. В этот период состоялась встреча лидеров СССР и США в Рейкьявике; осуществлены официальные визиты М.С. Горбачева в США и Р. Рейгана в СССР; достигнуты первые в истории советско-американских отношений договоренности по разоружению. Интересно узнать, как Вам удалось обратить внимание советского руководства на необходимость принятия энергичных мер по улучшению состояния дел в этой сфере?

Ю.Д. Дело в том, что это было время нарастания опасного противостояния между СССР и США. Обе стороны концентрировали свое внимание прежде всего на том, чтобы не упустить момент, когда противоположная сторона может первой нажать кнопку термоядерной войны. Правда, в 1985 г. уже состоялась встреча президентов двух стран в Женеве и, движимые надеждой, эксперты начинали очень осторожно говорить о духе «женевских договоренностей», однако маховик конфронтации был раскручен с такой силой, что, пожалуй, еще и после этого продолжал даже набирать обороты.

В Москве ходом дел в отношениях с США после встречи в Женеве были недовольны. Там М. С. Горбачев принял приглашение Р. Рейгана нанести визит в США. Но в Москве вставал вопрос, чего можно ждать от этой встречи. Оправдает ли она те большие надежды, которые связывались с ней во всем мире? Поисками ответа на эти вопросы объясняется и экстренное решение направить меня в Вашингтон. Проведенные встречи и беседы в американской столице, собранные наблюдения, о которых я доложил, побывав в Москве, вызвали большой интерес у советского руководства.

Было решено срочно подготовить развернутое послание М.С. Горбачева Р. Рейгану, направленное на, чтобы вывести США на конструктивные позиции по проблемам международной безопасности. Послание было нацелено на обеспечение результативности визита советского руководителя в США. По сути дела, это была целая программа преодоления холодной войны в сочетании с методологией движения к этой цели. В послании была дана откровенная оценка состояния отношений с США: «Мы разочарованы, как пошли наши дела после Женевы»; инициативы Советского Союза «не вызвали реального встречного движения со стороны США».

Далее с предельной откровенностью был изложен подход советской стороны к визиту в США: «без уверенности в достижении реальных соглашений не было бы смысла проводить такую встречу. Она лишь вводила бы в заблуждение общественное мнение и имела бы обратный эффект». Затем акцент в послании был перенесен на программу конкретных действий. Внимание сосредотачивалось на проблеме разоружения, и в частности на космических и стратегических наступательных вооружениях, на ракетах средней дальности в Европе, на прекращении ядерных испытаний.

Затрагивались и вопросы обычных вооружений, запрещения и уничтожения химического оружия, мирного урегулирования локальных конфликтов. Но послание не замыкалось только на кардинальных проблемах безопасности. В нем ставились и такие проблемы, как укрепление режима безопасности атомных электростанций, сотрудничество в мирном исследовании космического пространства, практические вопросы двусторонних отношений. Вместе с тем излагался и подход советской стороны к разработке решений по всем этим вопросам. Таков «ключ к осуществлению... решительного поворота в отношениях между СССР и США», - подчеркивалось в завершение послания.

Мне было поручено лично встретиться с президентом США, чтобы вручить ему послание и разъяснить его цели. Это было сделано. Таким образом, благодаря этой акции Советского Союза был дан импульс многогранной беспрецедентной дипломатической деятельности СССР и США по сбросу конфронтации, улучшению советско-американских отношений и преодолению холодной войны вплоть до начала 1990 г.

Интерес лично Рейгана концентрировался на дате визита М.С. Горбачева в США. Престиж Советского Союза в мире быстро нарастал и президент США не скрывал своего желания, чтобы советский лидер посетил США как можно скорее. Он предложил, чтобы это произошло уже в ноябре 1986 г. и просил Горбачева назвать конкретные даты. Но теперь сроки визита были поставлены в прямую зависимость от возможных договоренностей. И с обеих сторон были пред- 
приняты титанические усилия, чтобы такие договоренности были достигнуты.

Предметное ознакомление с научным и экономическим потенциалом США подвигло меня на выдвижение перед Москвой большого количества масштабных инициатив по развитию связей с США в различных областях. Было и еще одно измерение моей деятельности в США - это общение с американским народом. «Дубинины, - написала газета «Вашингтон пост» 15 мая 1990 г.», - наиболее популярные представители своей страны со времен Октябрьской революции 1917 г., вели самую широкую кампанию по связям с общественностью, которая когда-либо проводилась русскими в Соединенных Штатах». С лекциями, пресс-конференциями я посетил 38 штатов, некоторые по нескольку раз, добрался до Гавайских островов, открыл памятник первому русскому губернатору Аляски - легендарному Баранову. Я был частым гостем на радио и телевидении.

Н.А. Уважаемый Юрий Владимирович, в этот период Вы активно работали над тем, чтобы снять барьеры между нашей страной и деятелями культуры, науки, покинувшими ее в советский период. Поделитесь, пожалуйста, Вашими воспоминаниями, связанными со встречами с интересными людьми?

Ю.Д. В США я встретился с Мстиславом Ростроповичем, с которым впервые познакомился еще в 1956 г. в Париже. В начале февраля 1989 г. я сообщил М. Ростроповичу, что он восстановлен в Союзе композиторов СССР. На Ростроповича это произвело большое впечатление. Он сказал много слов признательности для передачи центральному руководству в Москву. 1 марта 1989 г. мною было передано М. Ростроповичу приглашение посетить Советский Союз для выступления в рамках фестиваля американского искусства. Он поблагодарил меня, но заявил, что первый раз после нескольких лет отсутствия хотел бы побывать в СССР не в составе американского мероприятия, а самостоятельно.

В Москве отнеслись к этому с пониманием. Некоторое время спустя была достигнута принципиальная договоренность о выступлениях в СССР Национального симфонического оркестра США, которым руководил М. Ростропович. Он был глубоко тронут сообщением, и я предложил объявить об этом на совместной пресс-конференции в середине апреля 1989 г. На встрече с журналистами - их было много - М. Ростропович был сильно взволнован. Это действительно был момент большой эмоциональной нагрузки. И не только эмоциональной, но и политической. Фотография, на которой взволнованный М. Ростропович обнимается с советским послом, обошла весь мир.

Через год был отъезд оркестра. Ростроповича провожал, как говорится, "весь Вашингтон". Концерт в "Кеннеди-Центре" с программой московского выступления, большой прием с напутственными речами и словами: "Слава, добро пожаловать на Родину". Возвращение после успешных выступлений оркестра в СССР было отмечено большим приемом, устроенным президентом Дж. Бушем в Белом доме. Был устроен прием и в советском посольстве.

Неоднократно я встречался со скульптором Э. Неизвестным. Как-то оказалась рядом моя внучка Катя. Ей было лет восемь. Она тянулась к карандашам и краскам. Узнав это, Э. Неизвестный взялся тут же рисовать с нею картину "в соавторстве". Произведение, весьма красочное, было быстро готово. И две подписи под ним: "Э. Неизвестный и ... Катенька". Таким образом, формы нашей культурной деятельности быстро обогащались. Русская открытость в сочетании с американской отзывчивостью и предприимчивостью помогали этому.

О приезде А.Д. Сахарова в США в середине ноября 1985 г. я узнал случайно. Никаких сообщений из Москвы не было. Сахаров к этому времени был освобожден от статуса затворника города Горького, но еще не полностью вписался в общественно-политическую жизнь Советского Союза. Внимание к нему в США было повышенным. Программа его пребывания была насыщенной. Она предусматривала и прием А.Д. Сахарова Р. Рейганом. Оставлять выдающегося ученого и крупного общественного деятеля нашей страны во время его поездки в США без внимания нашего посольства было бы неправильным, поэтому я незамедлительно сообщил организаторам визита А.Д. Сахарова о своем желании принять участие в наиболее важных из намеченных мероприятий. Организаторы поездки приветствовали такое решение. Начались встречи с обеда в Академии наук. Мое место за столом было рядом с А.Д. Сахаровым. Это было первое наше знакомство. А.Д. Сахаров оказался приятным и интересным собеседником.

К концу обеда у меня созрело решение пригласить его и желающих американских хозяев закончить вечер импровизированным приемом в посольстве. А.Д. Сахаров тотчас согласился с этим. Отправиться в посольство решили и все американские участники застолья. В посольстве ничего заранее не готовилось. Время было позднее. Но настроение у всех было хорошее, и все быстро сорганизовалось. Лиана, моя супруга, сама занялась кофе, чаем, появилось и все необходимое в таких случаях.

А.Д. Сахаров расспрашивал меня о переговорах по сокращению стратегических наступательных вооружений, которые СССР вел тогда с американцами. Вопросы у него были предметные и нацелены на самую суть целого ряда ключевых проблем, мешавших движению вперед. На меня произвело впечатление, что А.Д. Сахаров с полным пониманием относился и к занимаемым нами позициям, и к нашей аргументации. Затронута при этом была и проблема крылатых ракет морского базирования с ядерными боеголовками. Тут выдержанный А. Д. Сахаров поддался эмоциям.

- То есть как это они (американцы) утверждают, что невозможно решить вопрос о контроле над ними, - воскликнул он. - Да для этого никаких инспекторов на корабли сажать не требуется. Все 
можно сделать на расстоянии. Я скажу об этом Рейгану, все ему объясню», - заявил он. Американский президент ждал А.Д. Сахарова на следующий день. Конечно, не для разговоров по разоружению и тем более по такому деликатному вопросу, как сокращение крылатых ракет морского базирования - важной составляющей переговоров. Как мне потом рассказал сам Сахаров, Р. Рейган ограничился тем, что выслушал его мнение. В сообщении для печати о встрече американского президента с А.Д. Сахаровым об этой части их беседы Белый дом предпочел умолчать.

В 1989 г. в Советском Союзе впервые была избрана Мисс СССР. Событие получило международную огласку. Рядового американца оно убеждало, быть может, больше, чем многое другое, что в нашей стране действительно происходят нешуточные изменения. Реакция в США не заставила себя ждать: Мисс СССР - это была Юлия Суханова, получила приглашение от Мисс США - Дебби Тэрнер - совершить поездку в Соединенные Штаты и в начале октября оказалась в Вашингтоне.

Мною было дано поручение организовать прием по этому случаю в посольстве, который имел успех. Помимо приглашенных, залы посольства заполнила и вся армия теле- и фоторепортеров, которые следовали по пятам за королевами красоты сразу двух супердержав. На прием обратил внимание и президент США Дж. Буш. Его среди приглашенных не было. Но кадры об этом необычном протокольном мероприятии мелькали во всех телепрограммах. Я позволил себе назвать встречу Юлии и Дебби еще одним советско-американским саммитом - встречей на высшем уровне красоты и пожелать, чтобы в будущем наши страны состязались между собой только этим оружием.

Среди откликнувшихся на приглашение был один примечательный американец - директор весьма известного учреждения - Центрального разведывательного управления (ЦРУ) Уэбстер. Я не преминул предложить ему сфотографироваться вчетвером: две красавицы, посол и руководитель ЦРУ. Уэбстер не сопротивлялся и первый же оказавшийся рядом репортер немедленно обдал эту улыбающуюся группу залпом фотовспышек. Естественно, среди фотоснимков о приеме я стал искать именно этот. Но ни в одной из газете его не обнаружил. Не нашлось его и в коллекциях, которые обычно присылали в посольство после мероприятий фоторепортеры. При первой же новой встрече с Уэбстером я задал ему вопрос:

- Так где же он, мистер Уэбстер, тот снимок?

Улыбнувшись, Уэбстер ответил:

- О, мистер Дубинин, вы можете не сомневаться: он в надежном месте.

H.А. В Ваших мемуарах Вы уделяете внимание так называемой «операции по спасению китов», которая получила в США название «Breakthrough operation». Не могли бы Вы рассказать и об этих событиях?

Ю.Д. Слово «breakthrough» означает прорыв, выход на новое качество. Этим выражением пестрили в те дни страницы газет и журналов, сувенирные майки и спортивные костюмы. Вряд ли обозначишь точнее действия ледокола, сокрушившего ледовую твердь, чем назвав их «операция по прорыву». Но это выражение было точным и по другой причине: добрыми делами, понятными людям, взламывался и лед отчуждения между нашими странами, наросший за годы холодной войны, шаг за шагом создавалась новая атмосфера в советско-американских отношениях.

В 1989 г. зима пришла необычно рано. Уже во второй половине октября у берегов Аляски, обращенных к Северному полюсу, ударили сильные морозы. Весь Северный Ледовитый океан стал быстро обрастать панцирем льда. Обитавшие там серые киты обычно уходили на юг от надвигавшихся на свободную воду ледяных полей. Но на этот раз внезапно возникший ледовой барьер отрезал в районе мыса Барроу выход на морской простор трем китам. Они оказались запертыми льдами внутри своего рода озера большой полыньи.

Киты еще жили в этом водоеме, но стужа делала свое дело: незамерзшей поверхности воды оставалось все меньше, и китам грозила смерть. Их трагедию заметили с вертолетов. Об этом сообщили средства массовой информации. Новость быстро овладела вниманием всей Америки. Люди с нарастающей тревогой следили за все более мрачными сообщениями телеграфных агентств. Интерес к судьбе китов проявил Р. Рейган. Наше посольство тоже. Всеобщим желанием было помочь китам. Но как это сделать? Нечего было и помышлять о какой бы то ни было экспедиции по льдам. Драма происходила далеко от берега, лед быстро нарастал, и даже если бы люди высадились на него с вертолетов, справиться со льдом, пробить в нем проход они никак не смогли бы. Вертолетом кита, увы, тоже не подхватишь. Для освобождения китов требовался мощный ледокол. Только ему было под силу прорубить канал в перемычке из льда - лед был 40-60 см толщиной - и открыть китам путь к спасению. Но таких ледоколов у американцев не было, во всяком случае в том районе.

21 октября ко мне обратились представители американской общественности с просьбой изыскать возможность направить советский ледокол для спасения попавших в беду китов. Я написал в Москву: «Если наше участие в подобной операции практически возможно, то его следовало бы осуществить». В тот же день к посольству с официальной просьбой о помощи в спасении китов обратился и Госдепартамент. Он также рассчитывал на то, что мы сможем послать к мысу Барроу наш ледокол. Москва на мою телеграмму среагировала быстро и положительно. Посольству сообщили, что к спасательной операции было решено привлечь ледокол «Адмирал Макаров». Он находился в 300 милях от места происшествия. Резко сменив курс, ледокол направился на помощь китам. В операции принял также участие еще один наш ледокол - «Адмирал Арсеньев». 


\section{- История}

Госдепартамент, который был посольством проинформирован об этом решении, немедленно поставил в известность средства массовой информации. С этого момента Америка с пристальным вниманием следила за тем, какое расстояние отделяет наши ледоколы от полыньи, где были пленены киты. Люди победили. Пробив брешь во льдах, наши ледоколы открыли китам путь к спасению. Правда, на свободу вышли только два. По Америке прокатилась волна благодарности к нашей стране и советским морякам-полярникам.

В посольство шли письма и телеграммы, выражающие признательность. Меня пригласили провести пресс-конференцию в Нью-Йорке по этой теме. Министр торговли США Билл Верити устроил в январе 1989 г. специальную церемонию, на которой он от имени американской администрации передал мне, как советскому послу, памятные таблички и сувениры посольству, капитанам и экипажу ледоколов «Адмирал Макаров» и «Адмирал Арсеньев». Общественность США выступила с инициативой создания во Владивостоке скульптуры в честь спасения китов советскими моряками. Посольство эту инициативу поддержало, и вскоре скульптор Джефри Файбер отправился устанавливать ее.

Н.А. Уважаемый Юрий Владимирович, известно, что Ваша публичная деятельность находила широкий благожелательный отклик в США. Расскажите и об этом, пожалуйста.

Ю.Д. Вот как оценил эту деятельность госсекретарь США Дж. Бейкер на прощальном приеме в советском посольстве 10 мая 1990 г.: «На протяжении этих многих, иногда бурных, месяцев Юрий напоминал нам с достоинством, тактом и чувством юмора, что основная первоначальная функция посла остается в неприкосновенности. Он привнес в свою деятельность достойные восхищения верность и преданность делу, а также высокий профессионализм. Благодаря ему мы убедились в том, что отдельные личности в состоянии делать свои страны лучше. Короче говоря, он вновь продемонстрировал обеим сторонам, что человеческий фактор ничем нельзя заменить, независимо от того, далеко или близко находятся друг от друга страны и велики или малы возникающие вопросы. И если мы хотим гармонии, то нам особенно будут нужны мужчины и женщины, прекрасно владеющие искусством достижения гармонии - профессиональные послы, такие, как Юрий Дубинин».

Незадолго до отлета из США я был приглашен выступить в качестве главного гостя на выпускном акте международного факультета столичного университета Джорджа Вашингтона. Такого рода церемонии возведены в США в общенациональную традицию. Проходят они и в средних, и в высших учебных заведениях с большой торжественностью при участии не только преподавательского состава и студентов, но и родных, и друзей выпускников. Быть приглашенным на роль главного выступающего в такой церемонии в Америке почитают за большую честь государственные, политические и общественные деятели всех уровней, включая и президента. Задача такого выступающего - дать напутствие в жизнь оканчивающим учебное заведение. Руководство университета не только пригласило на эту роль меня, что в отношении посла нашей страны было сделано впервые. В своей речи президент университета Стефен Трахтенберг заявил: «Как Посол Союза Советских Социалистических Республик, Вы в течение четырех лет выполняли свою миссию во время беспрецедентного изменения в отношениях между двумя нашими странами. Вы проявили себя искусным и гибким государственным деятелем, когда враждебность уступила дорогу открытости, когда подозрительность сменилась надеждой, а американцы научились произносить слова «гласность» и «перестройка» также легко, как они произносят "бейсбол" и "яблочный пирог"...

Возможно, - подчеркнул он, - самым ярким и убедительным свидетельством меняющихся отношений между нашими странами, тех отношений, которым Вы служили и которые пестовали, американский университет, носящий имя отца-основателя Соединенных Штатов Америки, по случаю присвоения вам степени Доктора гражданской службы этого университета».

Я покинул Вашингтон за две недели до визита в США М.С. Горбачева, когда он дал согласие Дж. Бушу на вхождение ФРГ в НАТО, открыв, по сути дела, этому военно-политическому союзу, к изумлению даже самих американцев, путь на Восток...

Anikeeva N.E. The memories of distinguished diplomat Yury Vladimirovich Dubinin. 